
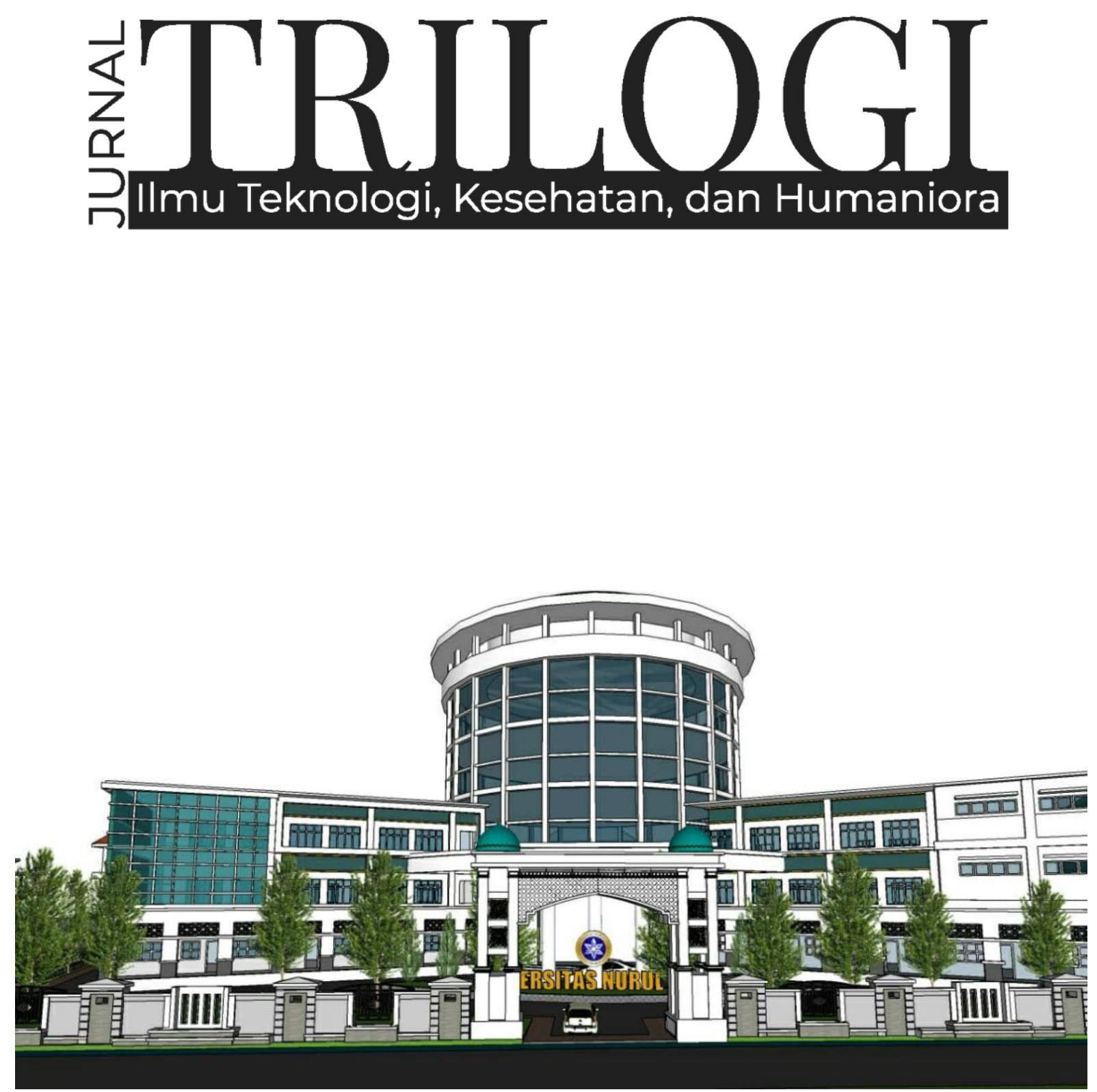

PENGEMBANGAN PENDIDIKAN DAN EKONOMI PESANTREN DI MASA PANDEMI COVID-19 


\section{犃BUOGI}

Vol. 2, No. 2, 2021

Editor in Chief

Achmad Fawaid, (SCOPUS ID: 57214837323)

\section{Managing Editors}

Hasan Baharun, (ID SCOPUS : 57200983602)

Sugiono Sugiono, (SCOPUS ID : 57199578160)

Ismail Marzuki, (SCOPUS ID: 57201500245

Subhan Rachman, (SCOPUS ID: 57192937912)

Nurul Huda, (SINTA ID: 6119615)

Syamsuri, (SINTA ID: 6116825)

Ridhatullah Assya'bani, (SINTA ID: 6200862)

\section{Peer Reviewers}

Miftahul Huda, (SINTA ID: 6171566), University of Antwerp, Belgium

Achmad Naufal Irsyadi, (SINTA ID: 6704870), Universitas Nurul Jadid, Indonesia

Gulpi Qorik Oktagalu P., (SINTA ID: 5982074) Universitas Nurul Jadid Probolinggo, Indonesia Hozairi, (SINTA ID: 166198), Universitas Islam Madura, Indonesia

Nur Hamid, (SINTA ID : 6744813), Univeristas Nurul Jadid Probolinggo, Indonesia Zainal Munir, (SINTA ID: 6672512), Universitas Nurul Jadid Probolinggo, Indonesia Sri Astutik Andayani, (SINTA ID: 6172559), Universitas Nurul Jadid Probolinggo, Indonesia Sukamto Sukamto, (SINTA ID: 5979034), Universitas Widya Gama Malang, Indonesia Deny Utomo, (SINTA ID: 6016108), Universitas Yudharta Pasuruan, Indonesia Fariz Alnizar, (SCOPUS ID: 6659824), UNUSIA Jakarta, Indonesia

Fuad Rahman, (SCOPUS ID: 57201474778), UIN Sulthan Thaha Saifuddin Jambi, Indonesia Saifuddin Zuhri Qudsy, (SCOPUS ID: 57213595165), UIN Sunan Kalijaga Yogyakarta, Indonesia Akhmad Anwar Dani, (SINTA ID: 14305), IAIN Surakarta, Indonesia

Maufur Maufur, (SINTA ID: 5989329), IAIN Kediri, Indonesia

Siti Mahmudah Noorhayati, (SINTA ID: 6726997), IAIN La Roiba Bogor, Indonesia Busro Busro, (SCOPUS ID: 57205022652), UIN Sunan Gunung Djati Bandung, Indonesia Akmal Mundiri, (SCOPUS ID: 57205059378), UNUJA Probolinggo, Indonesia

\section{Section Editor}

Ahmad Zubaidi, Universitas Nurul Jadid, Probolinggo, Indonesia 
TRILOGI: Jurnal IImu Teknologi, Kesehatan, dan Humaniora is a peer-reviewed journal, open-access journal which publishes original articles on various issues within technology, health, and social humanities, which include but are not limited to newrenewable energy, food-agriculture, health-pharmacy, transportation, informationcommunication technology, advanced-materials, maritime-infrastructre, social-artseducation, and religious studies based on academic and scientific research.

TRILOGI: Jurnal IImu Teknologi, Kesehatan, dan Humaniora seeks to publish a balanced mix of theoretical or empirical articles, case studies, review papers, comparative studies, exploratory papers, and book reviews. All accepted manuscripts will be possibly published both online and in printed forms.

Editorial Office:

TRILOGI: Jurnal IImu Teknologi, Kesehatan, dan Humaniora Lembaga Penerbitan, Penelitian, dan Pengabdian kepada Masyarakat (LP3M) Universitas Nurul Jadid, Paiton, Probolinggo, Jawa Timur, Indonesia 67291.

Phone: 088830 77077, Hp: 082318007953

Email: jurnal.trilogi@gmail.com

Website: https://ejournal.unuja.ac.id/index.php/trilogi/index 


\section{Tables of Content}

71-76

Pengaruh Metode Pembelajaran Daring dengan Aplikasi Google Classroom terhadap Hasil Belajar Siswa Madrasah Ibtidaiyah Nurul Mun'im Paiton Probolinggo

Feriska Listrianti, Lailatul Munawwaroh, Sayyidatul Arifa, Siti Aisyah

77-84

Inklusivitas dan Responsivitas Pesantren dalam Penanganan Pandemi Covid 19: Telaah Hidden Curriculum Pembelajaran di Pondok Pesantren Nurul Jadid

Zakiyah BZ, Uswatun Hasnah, Nafistur Rahmah

84-94

Integrasi Kurikulum Madrasah Diniyah dengan Lembaga Formal dalam Meningkatkan Mutu Lulusan di Sekolah Menengah Pertama (SMP) Nurul Jadid Paiton Probolinggo

Abdurrahman, Ika Fitri Anwar, Sofiya Mauliza, Nadya Afkarina

95-104

Some Issues on Time Deposit Financing: An Islamic Perspective on Mudharabah Agreement at Baitul Maal wa Tamwil (BMT) NU in Randuagung Lumajang

Saifuddin, Abdul Hafid, Hengki Wahyu Pratama

$105-110$

Analisis Pengembangan Potensi Ekonomi Keluarga melalui Unit Usaha Kapuk

Fahrudin, Iis Sa'diyah, Rizaldi Chandra Gunawan

111-117

Penguatan Ekonomi Pesantren melalui Pengembangan Ekonomi Masyarakat Pesisir: Pelajaran dari Pondok Pesantren Nurul Jadid Paiton Probolinggo

Achmad Febrianto, Muhammad Habibullah, Aksal Ilhamsyah

118-125

Prevensi Perilaku Konsumtif Persepektif Abraham Maslow dan Tri Logi Santri

Muhammad Syaiful Suib, Habibatur Rizkiyah, Fitria Nur Ain 
$126-136$

Manajemen Pengembangan Kurikulum Berorientasi pada Pembentukan Karakter

Moh Rifa'i, Fatimah Al Zahra, Abdurrahman Abdurrahman, Mukhlisin Saad

137-147

Home Industry, Kaderisasi, dan Santripreneur

Muh Hamzah, Aprilinda Dwi Kurniawati, Husnul Khotimah

148-157

Rancangan Pengelolaan Nirsampah Mandiri Skala Lembaga Pendidikan

Tirmidi, Eril Sinta Nuriyah, Rofi'ah

158-166

Parents' Knowledge and Commitment To Stimulate Child Development

Lailatul Fitriyah, Nurul Islamiyah, Auliya' Fatahillah

167-172

Implementasi Pembelajaran Akhlak Berbasis Multikultural pada Masa Pandemi di Madrasah Tsanawiyah Nurul Jadid Paiton Probolinggo

Abdullah, Yusrolana, Nur Laily

$173-183$

Implementasi Evaluasi Pembelajaran Daring (Online) melalui Home Visit

Moch Tohet, Moh. Bagus Abdillah, Adam Hakim Al Rizki

184-192

Efektivitas Pembelajaran Luring pada Mata Pelajaran Matematika selama Pandemi Covid-19

Zaenol Fajri, Sukron Junaidi, Hamdani Alfarisi 
P-ISSN: 2774-4574; E-ISSN: 2774-4582

TRILOGI, 2(2), Mei-Agustus (105-110)

@2021 Lembaga Penerbitan, Penelitian, dan Pengabdian kepada Masyarakat (LP3M)

Universitas Nurul Jadid Paiton Probolinggo

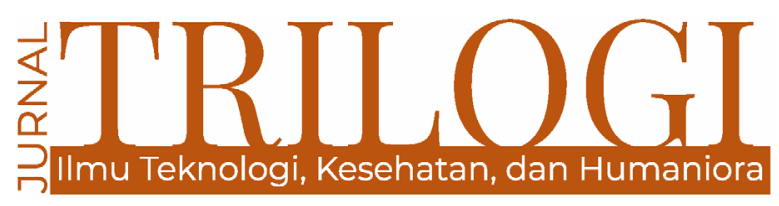

\title{
ANALISIS PENGEMBANGAN POTENSI EKONOMI KELUARGA MELALUI UNIT USAHA KAPUK
}

\section{Fahrudin}

Universitas Nurul Jadid, Probolinggo

fahrudin@unuja.ac.id

\section{Iis Sa'diyah}

Universitas Nurul Jadid, Probolinggo

iissa7259@gmail.com

\section{Rizaldi Chandra Gunawan}

Universitas Nurul Jadid, Probolinggo

rizaldichandra0909@gmail.com

\begin{abstract}
This study aims to analyze one of the business potentials of Sumurdalam Village, Besuk District, namely the home industry of cotton (kapuk). This study uses a qualitative descriptive method through interview and observation techniques to obtain a data of the development of the Kapuk. Kapuk business is a home industry that produces small-scale products but has the potential to improve the family economy. The family living cost can be achieved if they have certain knowledge and skills in managing the business, so they can truly become micro entrepreneurs. The results of this study are: a) increasing public awareness of harmony and planting cooperation; b) Half income from production costs; c) Products of various motifs, types, sizes and competitiveness; d) offline and online marketing strategies; and e) affordable product prices. This cotton business can develop rapidly by prioritizing quality and trust in its efforts.
\end{abstract}

Keywords: Economic Potential; Cotton Business; Home Industry 


\begin{abstract}
Abstrak
Penelitian ini bertujuan untuk menganalisis salah satu potensi bisnis Desa Sumurdalam Kecamatan Besuk, yakni industri rumahan melalui Unit Usaha Kapuk. Penelitian ini menggunakan metode deskriptif kualitatif melalui teknik wawancara dan observasi untuk memperoleh gambaran perkembangan Unit Usaha Kapuk tersebut. Usaha Kapuk merupakan industri rumahan yang menghasilkan produk berskala kecil namun berpotensi meningkatkan ekonomi keluarga. Peningkatan ekonomi keluarga dapat dicapai jika mereka memiliki pemahaman dan keterampilan tertentu dalam mengelola usaha tersebut, sehingga mereka bisa benar-benar menjadi pengusaha mikro. Hasil dari penelitian ini yaitu: a) meningkatnya kesadaran masyarakat akan kerukunan dan penanaman kerjasama; b) penghasilan separuh dari biaya produksi; c) produk berbagai motif, jenis, ukuran dan berdaya saing; d) strategi pemasaran offline dan online; dan e) harga produk yang terjangkau. Usaha Kapuk ini dapat berkembang pesat dengan mengutamakan kualitas dan kepercayaan dalam usahanya.
\end{abstract}

Kata kunci: Potensi Ekonomi; Usaha Kapuk; Industri Rumahan

\section{Pendahuluan}

Di Indonesia terdapat banyak berbagai macam usaha, mulai dari usaha mikro, kecil sampai menengah, yang tertuang dalam Undang-Undang Nomor 20 Tahun 2008 Tentang Usaha Mikro Kecil Dan Menengah. Meningkatkan ekonomi dalam keluarga banyak berbagai cara yang dilakukan, hal ini menjadi tanggung jawab kepala keluarga. Masa sekarang cukup sulit dalam mencari pekerjaan yang bisa mencukupi keluarga apalagi dengan adanya pandemi Covid-19. Kondisi lowongan pekerjaan selalu tidak sesuai dengan jumlah calon pekerja. Banyaknya masyarakat yang belum dapat pekerjaan sehingga menambah deretan pengangguran. Seiring dengan perkembangan industri saat ini, kita dituntut berfikir kreatif dan inovatif dengan begitu tidak tergantung pada usaha orang lain.

Pendapatan yang sesuai adalah pendapatan yang bisa memenuhi kebutuhan hidup seharihari berbeda dengan keinginan. Suatu profesi biasanya dapat dilihat dari kehidupan sosialnya. Semua orang mempunyai hak dan kewajiban tertentu, hak untuk mendapatkan sejahtera dan kewajiban memilih profesi untuk kehidupan kedepannya. Demi mencapai suatu kesejahteraan, maka keadilan bagi seluruh rakyat Indonesia harus diutamakan, baik keadilan mendapatkan pelayanan dan keamanan, maupun keadilan dalam memperbaiki sehidupan sehari-hari demi kebutuhan keluarga. Keadilan semacam itu menjadi hak asasi manusia.

Untuk menentukan apa yang terbaik dalam memenuhi kebutuhan kehidupannya. Hal ini termasuk dalam menentukan profesi yang akan digeluti demi memenuhi kehidupan semua anggota keluarganya. Industri menjadi wadah menampung pekerja sebagai profesi yang sesuai kebutuhan perusahaan tersebut. Menurut Bintarto (1977:87), industri adalah setiap usaha yang merupakan unit produksi yang membuat suatu barang atau mengerjakan suatu barang (bahan) di suatu tempat tertentu untuk keperluan masyarakat.

Desa Sumurdalam merupakan Desa yang terletak di Kecamatan Besuk yang rata-rata didominasi oleh rakyat kecil sampai menengah. Kurang lebih 70 persen pengolah dan pengusaha Kapuk. Usaha ini telah mereka lakukan bertahun tahun dan turun temurun. Namun usaha ini masih terbilang usaha rumahan atau usaha kecil dengan peralatan yang masih sederhana. Pengelolaan kapuk ini dilakukan setiap keluarga dan kerabat dekat saja, bahkan pemiliknyapun demikian. Usaha tersebut dimiliki, dikelola, dan diperjualkan. Ada juga terkadang dikelompokkan hasil produknya dan dijual ke pemesan. Masyarakat Desa tersebut sangatlah mahir dalam pengelolahan kapuk karena pengelola sekarang sudah sejak lahir orang tua mereka menggeluti profesi ini.

Kelangkaan bahan berupa kapuk tidak membuat masyarakat pengelola behenti memproduksi. Pengelola menyiasati dengan cara memasok dari Desa luar, seperti pati, gunung malang, dan sebagainya. Selain itu, selain memakai kapuk sebagai bahan utama, masyarakat terkadang langsung menjual sebagian hasil kapuk kepada pengusaha Kapuk lain juga, alasannya pertama mencukupi kebutuhan ekonomi yang menDesak, kedua kelebihan bahan baku kapuk pada saat itu. Pengusaha Kapuk harus mempunyai strategi dalam pemasaran produknya.

Konsep utama dalam pengukuran permintaan adalah permintaan pasar dan permintaan peru- 
sahaan. Dalam masing-masing konsep itu, kita harus membedakan antara fungsi permintaan, peramalan penjualan, dan potensi. Langkah utama pemasar dalam mengevaluasi peluang pasar adalah memperkirakan total permintaan pasar (Kotler dan Keller, 2000:123). Permintaan pasar bukan suatu yang pasti, maka Masyarakat pengusaha Kapuk mempertimbangkan hal tersebut dalam memproduksi hasil dari bahan kapuk.

Berdasarkan hal diatas, diperlukan pendampingan dan pengembangan potensi usaha keluarga yang ada dalam Usaha Kapuk. Dengan meningkatkan potensi juga kreativitas akan menunjang keberlangsungan Usaha Kapuk.

\section{Metode}

Penelitian dilakukan di Kecamatan Besuk Kabupaten Probolinggo tepatnya di Desa Sumurdalam Dusun Kasur RT/RW 09/03. Penelitian ini dilakukan mulai pengajuan judul tanggal 13 Januari 2021 dan mulai menentukan lokasi serta kegiatan sampai dengan tanggal 29 April 2021. Mengawali penelitian dengan menuju kepala Desa untuk koordinasi. Dukungan dari kepala Desa setempat sangat dibutuhkan dan keterlibatan pengusaha Kapuk Desa Sumurdalam demi kelancaran penelitian.

Studi ini menggunakan metode deskriptif kualitatif, karena penelitian ini menghasilkan datadata yang merupakan gambaran perkembangan unit Usaha Kapuk yang sudah berjalan di Desa Sumurdalam. Data-data yang diperoleh dapat menggambarkan objek yang diteliti sesuai dengan keadaan yang sebenarnya dilapangan.

Data yang diperoleh dalam penelitian ini bersumber dari data primer dan data sekunder. Data primer yaitu data yang diperoleh langsung dari sumbernya. Diambil dan dicatat dari lapangan. Data primer dalam penelitian ini yaitu data yang berkaitan dengan unit Usaha Kapuk diperoleh melalui wawancara. Data sekunder yaitu data yang diusahakan sendiri pengumpulannya oleh peneliti. Data sekunder dalam penelitian ini berupa literasi yang berkaitan dengan materi penelitian. Adapun metode pengumpulan data sebagai berikut:

a. Wawancara, yaitu dengan melakukan tanya jawab secara langsung dengan pengelola unit Usaha Kapuk;

b. Kepustakaan (library research), yaitu pengumpulan data dengan cara mengumpulkan bahan- bahan dari berbagai literasi untuk memperoleh dasar teoritis;

c. Observasi, mengumpulkan data dengan cara mengamati objek yang diteliti secara langsung.

\section{Hasil dan Pembahasan}

\section{a. Identifikasi Usaha Kapuk}

Penelitian dilakukan di Kecamatan Besuk tepatnya di Desa Sumurdalam Dusun Kasur RT/ RW 09/03. Desa Sumurdalam ini kurang lebih 70 persen pengolah dan pengusaha Kapuk selebihnya petani dan pekerja buruh. Usaha Kapuk ini dilakukan sudah turun temurun sejak tahun 90an ( \pm 1990$)$ sampai saat ini masih memproduksi produk bantal, kasur dan guling. Usaha ini masih terbilang usaha rumahan (home industri), dan bisa dibilang usaha kecil dengan pembuatan produk tersebut menggunakan bahan dan alat yang masih sederhana. Menurut Mulyani (2008), Home industri adalah perusahaan dalam skala kecil, biasanya perusahaan ini hanya menggunakan satu atau dua rumah sebagai pusat produksi, administrasi dan pemasaran sekaligus secara bersamaan. Usaha Kapuk ini merupakan home industry, karena beberapa alasan. Pertama, lingkup kecil dan keahlian warisan dari orang tua sehingga berfikir jangan sampai dilupakan. Kedua, mencari nafkah dengan usaha olahan kapuk; ketiga, dikerjakan oleh kerabat dekat, dan masih banyak sebab lainnya.

Pengelolahan dan pembuatan produk bahan kapuk dilakukan oleh kerabat dekat saja, sehingga usaha ini merupakan usaha keluarga. Jadi satu kepala keluarga mempunyai satu usaha. Produk tersebut dikelola, dibuat, dan sampai dijual sendiri. Terkadang, hasil produk dikumpulkan dengan hasil kepala keluarga yang lainnya di Desa tersebut lalu dijual bersamaan. Hal ini dikarenakan pemesan yang membutuhkan stok banyak.

Kelangkaan bahan kapuk tidak membuat masyarakat berhenti produksi. Pengelola menyiasati dengan cara memasok bahan kapuk dari luar daerah dengan cara kesepakatan bayar setelah ada hasil penjualan produk. Memasok dari luar daerah seperti Betek, Gunung Malang, Pati, Bali dan lain sebagainya. Selain kapuk sebagai bahan utama terkadang saat mendapatkan kapuk dengan harga murah dan banyak, mereka langsung menjual sebagian kapuknya kepada pengusaha lainya yang serupa. Dengan beberapa alasan, yang salah satunya kebutuhan ekonomi yang menDesak, membutuhkan biaya untuk beli bahan, dan lain sebagainya. 
Suatu usaha tentu tidak berjalan selalu mulus, usaha ini juga mengalami kendala. Fakta dilapangan terdapat penemuan rata-rata masyarakat yang Usaha Kapuk terkendala biaya meskipun tidak selalu terjadi. Kendala lainnya yaitu terkadang pengusaha mendapat kapuk yang kurang bagus sehingga selalu menyiasati kapuk tersebut dicampur dengan yang lebih bagus. Hal ini dilakukan ketika pemesan ingin hasil yang bagus dengan harga yang murah.

\section{Analisis Pengembangan Usaha Kapuk}

Saat ini Desa Sumurdalam berdasarkan survey lapangan kurang lebih 25 kepala keluarga memproduksi produk yang bahan dasar kapuk. Dalam mendapatkan bahan kapuk tersebut saat ini ada sebagian menjadi pengepul kapuk. Salah satunya sapaan akrab disana bapak $\mathrm{H}$. Heli dan bapak Muhammad, masyarakat sekitar yang memprodukdi kasur mengambil kapuk digudangnya dengan membeli. Harga yang dipatok kisaran 200 - 275 ribu rupiah per satu kwintalnya. Ada juga pengrajin kapuk yang tidak ada biaya tapi ingin memproduksi bisa mengambil bahan kapuk dulu dengan kesepakatan bayar setelah hasil produk laku terjual.

Berdasarkan informasi yang didapat kapuk 1 kwintal dapat menghasilkan dua kasur sekaligus. Sedangkan kapuk 1 kwintal tersebut masih dalam kulitnyayang kering, dan masih perlu pemisahan kulit dan bijinya. Tak jarang kulit kapuk tadi dijual kembali karena tidak terpakai dan sebagai tambahan dana untuk biaya bahan meskipun sedikit. Terkadang pengrajin mendapat kapuk jelek yang sudah kena hujan, hal ini menambah deretan proses produksi sehingga menyiasati kapuk tersebut terpakai dengan campuran kapuk yang bagus pada saat produksi. Berikut rincian Usaha Kapuk yang digeluti oleh warga Desa Sumurdalam.

Tabel 1. Alat dan Bahan

\begin{tabular}{ccc}
\hline NO & BAHAN & ALAT \\
\hline 1 & Kapuk & Jarum \\
\hline 2 & Kain & Mesin Jahit \\
\hline 3 & Benang & Meteran \\
\hline 4 & & Gunting dan pisau \\
\hline 5 & & Alat tulis \\
\hline 6 & & Kayu modifikasi \\
\hline
\end{tabular}

Tabel 2. Produk dan Harga

\begin{tabular}{lll}
\hline NO & PRODUK & HARGA (Ribu) \\
\hline 1 & Kasur & Standar : $300-350$ \\
& & Besar : 400-800 \\
& & VIP (lebih tebal): $800-1$ jt \\
\hline 2 & Bantal & $25-45$ \\
\hline 3 & Guling & $50-70$ \\
\hline
\end{tabular}

Berdasarkan table.1 dan table.2, terlihat peralatan yang digunakan Usaha Kapuk cukup sederhana dan harga yang dipatok bisa dibilang terjangkau bagi semua kalangan masyarakat. Dengan harga yang terjangkau pengrajin merasa cukup mendapatkan hasil dari penjualan produknya. Kasur VIP yang dimaksud adalah kasur yang dengan bahan bagus dari kain, kapuk, hingga ukuran lebih tebal biasanya ini dipesan secara langsung ke pengrajin.

Adapun urutan proses produksi ini mulai dari bahan baku hingga menjadi produk jadi, sebagai berikut.

1) Bahan baku yang dibutuhkan dalam proses produksi yaitu kapuk kering;

2) Pemisahan yaitu proses pemisahan bahan kapuk dengan kulit dan bijinya menggunakan alat manual;

3) Bahan kain dijahit menggunakan mesin jahit sesuai ukuran kasur, bantal, dan guling;

4) Pengisian kapuk ke dalam kain yang telah dibuat dengan kayu modifikasi;

5) Kasur yang sudah jadi kemudian dijahit kembali;

6) Pengemasan kasur yang sudah jadi;

7) Penyimpanan hasil produk siap dijual.

\section{b. Potensi Usaha Kapuk}

Berdasarkan survey lapangan dan wawancara terhadap pengrajin dan pengguna produk dari bahan kapuk dapat menemukan keadaan dan pernyataan. Sehingga peneliti dapat menulis dalam kelebihan dan kekurangan potensi Usaha Kapuk Desa Sumurdalam, sebagai berikut:

\section{1) Kelebihan}

a) Terbuat dari bahan alami yang dihasilkan dari buah randu, kasur kapuk memiliki bobot yang jauh lebih ringan ketimbang spring bed;

b) Jenis kasur ini hanya mengandalkan serat kapuk dan lapisan sarung kasur saja sehingga ringan, dibandingkan kasur spring bed yang terdiri dari komponen yang banyak dan berat seperti per; 
c) Karena terbuat dari bahan kapuk sehingga tidak panas/ruam saat digunakan;

d) Pelanggan atau pemesan dapat memilih motif kain dan ukuran sesuai selera langsung ke lokasi serta dapat harga lebih murah daripada ke pertokoan;

e) Pengrajin tidak terikat waktu kerja karena usaha dimiliki sendiri;

f) Pengrajin membuat sesuai kemampuan dan atau sesuai keinginan pemesan;

g) Pelanggan tetap ada yang dari mulai toko kecil sampai besar, mebel, sales dan sebagainya mempercayai karena sudah lama usaha ini ada dan kerjasama sudah lama terjalin;

h) Karena terbuat dari bahan alami sehingga terbilang tahan lama;

i) Pemasaran sudah keluar dari Kabupaten Probolinggo yaitu Kab. Pasuruan, Kab. Situbondo dan Bali.

\section{2) Kekurangan}

a) Sebagian besar pengrajin saat membuat menggunakan cara manual meskipun juga dibantu oleh mesin;

b) Pembuatan membutuhkan waktu cukup lama;

c) Menunggu dan atau mencari bahan baku yaitu kapuk yang mulai langka;

d) Proses mendapatkan serat kapuk kering cukup lama dari dijemur, dikupas, pemisahan kulit dan bijinya (mensortir);

e) Pengrajin sebagian warga kurang mampu sehingga terkendala biaya;

f) Pengrajin dapat membuat hanya lingkup kecil saja;

g) Biji kapuk terkadang masuk dalam pembuatan kasur;

h) Penjualan sedikit menurun karena adanya pandemi.

\section{c. Keberlangsungan Ekonomi Melalui Usaha Kapuk}

Situasi kelangkaan kapuk tidak membuat pelaku industri ini berhenti produksi, dan sebaliknya membuat usaha ini harus melebarkan sayap yang artinya menambah atau memperluas wilayah pemasok kapuk. Hal ini dilakukan menambah lokasi keberadaan kapuk, dengan cara membeli pohon dan dipelihara sampai batas sesuai kesepakatan, lokasi tambahan yaitu daerah Prasi, Teres, Rabunan dan Besuki. Lokasi ini menjadi pemasok tambahan kapuk ke depannya. Selain itu ada beberapa orang yang menjadi pemasok kapuk baru ke Desa Sumurdalam, sehingga keberlangsungan ekonomi Usaha Kapuk bertahan bahkan lebih berkembang.

Pengrajin memasarkan hasil produksi dengan strategi pemasaran, yaitu:

1) Memasok barang hasil produksi ke daerah yang telah menjadi langganan tetap mereka (pasar maron, pasar tiris, pasar wangkal, dan lain sebagainya);

2) Pemasaran dari mulut ke mulut;

3) Menjajahkan keliling yang bisa dijangkau;

4) Menerima pesanan dari pelanggan tetap atau baru;

5) Kurang lebih 3 tahun terkhir mengunakan aplikasi online (tokopedia, bukalapak, shopee, WhatsApp, dan lain sebagainya).

Home industry ini dijalani oleh masyarat dengan penghasilan separuh dari biaya pembuatan yang digunakan, sehingga omset ditaksir hasilnya dua kali libat dari setiap produk, dengan hasil kotor. Dimisalkan harga kasur 400 ribu berarti biaya pembuatan 200 ribu. Usaha Kapuk ini juga menggiurkan bagi masyarat dilihat dari hasil, ketekunan mereka, dan merasa mudah karena terbiasa serta tidak terikat waktu kerja.

Keberlangsungan Usaha Kapuk sangat erat dengan hubungan emosional dan moral, ini dikarenakan keluarga sebelumnya mewariskan keahlian dan kepercayaan atas keberlanjutan usaha demi keluarga. Kedepan Usaha Kapuk ini akan berinovasi, yang awalnya membuat kasur, bantal, dan guling. Pemuda sekitar berencana juga membuat souvenir, boneka, dan gantungan kunci. Sehingga ada perkembangan dan kemajuan kedepan demi meningkatkan ekonomi keluarga.

\section{Kesimpulan}

Berdasarkan analisis diatas yang sudah dipaparkan secara keseluruhan dapat disimpulkan. Bahwasannya Sumurdalam merupakan salah satu Desa pengahasil produk berbahan kapuk terbesar di Kabupaten Pobolinggo. Produknya meliputi kasur, bantal dan guling. Industri kapuk di Desa Sumurdalam hanya sebatas home industri yaitu lingkup kecil dan seluruh pengerjaannya dilakukan oleh pemilik usaha beserta kerabat dekatnya. Proses pembuatan dilakukan secara manual dengan alat-alat yang masih sederhana. Usaha Kapuk Desa Sumurdalam kurang dikenal di Kabupaten Probolinggo. Namun, pemasaran sudah keluar kabupaten probolinggo yaitu Kabupaten Situbodo, Pasuruan, dan Bali. Hal ini menjadikan 
industri maju dan berkembang serta masih banyak target-target pemasaran kedepannya. Keberlangsungan Usaha Kapuk yang berpotensi ini dapat berkembang pesat dengan mengutamakan kualitas dan kepercayaan dalam usahanya.

\section{Daftar Pustaka}

Agustyawati, D. (2018). Penerapan Metode Harga Pokok Proses Dalam Penentuan Harga Jual Produksi Kasur Pada Usaha Kasur Membali Jaya Di Kota Baubau. Jurnal I/miah Akuntansi Manajemen. 1(2), 35-43. Diakses 3 Juli 2021. http://jurnalumbuton.ac.id/ index.php/jiam/article/view/247

Anindita,H. (2021). Usaha Mikro adalah Sektor yang Meningkatkan Perekonomian Indonesia. Blog: JOJONOMIC Diakses 26 Juni 2021. https://www.jojonomic.com/ blog/usaha-mikro/

Hidayah,U. dkk. (2020). Optimalisasi Unit Usaha Bumdes Harapan Jaya Berdasarkan Potensi Lokal Di Desa Pagelaran. Jurnal Benefita, 5(1), 101-112. Diakses 17 Mei 2021. https://www.researchgate.net/profile/ Ulul-Hidayah-2/publication/341704303_ OPTIMALISASI_UNIT_USAHA_BUMDES_ HARAPAN_JAYA_BERDASARKAN POTENSI_LOKAL_DI_DESA_PAGELARAN/ links/5eede69e299bf1faac665929/ OPTIMALISASI-UNIT-USAHA-BUMDESHARAPAN-JAYA-BERDASARKAN-POTENSILOKAL-DI-DESA-PAGELARAN.pdf

Kamil, A. (2015). Industri kreatif indonesia: pendekatan analisis kinerja industri. Jurnal Media Trend, 10(2), 165-182.

Kotler, Philip \& Keller, K. L. (2009). Manajemen Pemasaran Edisi Ketiga Belas Jilid 2. Jakarta: Erlangga.

Purwanto, A. (2020). Potret dan Tantangan UMKM di Indonesia. KOMPAS PEDIA. Diakses 20 Mei 2021. https://kompaspedia.kompas.id/ baca/paparan-topik/potret-dan-tantanganumkm-di-indonesia
Sugiyono. (2017). Metode Penelitian Bisnis (Pendekatan Kuantitatif, Kualitatif, dan R\&D). Bandung: Alfabeta.

Syuhada, Siti. (2014). Analisis Perkembangan Unit Usaha Dan Penyerapan Tenaga Kerja Serta Pengaruhnya Terhadap Pendapatan Keluarga Pada Usaha Mikro, Kecil Dan Menengah Berbasis Pangan Olahan Di Kecamatan Pelayangan Kota Jambi. Jurnal Neliti, 16(1), 23-28. Diakes 28 Mei 2021. https:// www.neliti.com/publications/43457/ analisis-perkembangan-unit-usahadan-penyerapan-tenaga-kerja-sertapengaruhnya-t

Tanjung, M. Azrul. (2017), Koperasi dan UMKM sebagai fondasi Perekonomian Indonesia. Jakarta: Erlangga.

Ulfa, N. A. (2017). Studi Usaha Pembuatan Kasur di Desa Bumiharjo Kecamatan Batanghari Tahun 2017. Jurnal Penelitian Geografi. 5(9), 1-10. Diakses 23 Juni 2021. http:// jurnal.fkip.unila.ac.id/index.php/JPG/ article/view/14858

Wantara, Pribanus. (2018). Hubungan Pemasaran Internal Dan Kepuasan Pelanggan. Prosiding universitas wiraraja. Hal 36-42. Diakses 1 Juni 2021. https://www.ejournalwiraraja. com/index.php/PRD/article/view/513

Yanuarti, D. W. (2018). Pengaruh Orientasi Kewirausahaan Terhadap Kinerja Pemasaran Melalui Strategi Bersaing Dan Kapabilitas Pemasaran Pada Industri Kasur Kapuk Di Kabupaten Pati. UNNES: Skripsi. Diakses 17 Mei 2021. http://lib.unnes. ac.id/38080/1/7311414122.pdf

Yaqin, M. A. (2019). Pengembangan Strategi Penjualan Hasil Pengolahan Kapuk Di Desa Sumurdalam Melalui Media Online. Madani : Indonesian Journal Of Civil Society, 18(1), 1-4. Diakses 9 Mei 2021. https:// www.ejournal.pnc.ac.id/index.php/madani/ article/view/60 